\title{
Improving biodiversity monitoring
}

David B. Lindenmayer ${ }^{1 *}$, Philip Gibbons ${ }^{1}$, Max Bourke², Mark Burgman ${ }^{3}$, Chris R. Dickman ${ }^{4}$, Simon Ferrier ${ }^{5}$, James Fitzsimons ${ }^{6}$, David Freudenberger ${ }^{7}$, Stephen T. Garnett ${ }^{8}$, Craig Groves $^{9}$, Richard J. Hobbs ${ }^{10}$, Richard T. Kingsford ${ }^{11}$, Charles Krebs ${ }^{12}$, Sarah Legge ${ }^{13}$, Andrew J. Lowe ${ }^{14}$, Rob McLean ${ }^{2}$, Jensen Montambault ${ }^{15}$, Hugh Possingham ${ }^{16}$, Jim Radford ${ }^{17}$, Doug Robinson ${ }^{18}$, Lisa Smallbone ${ }^{19}$, David Thomas ${ }^{2}$, Tony Varcoe ${ }^{20}$, Michael Vardon ${ }^{21}$, Glenda Wardle ${ }^{4}$, John Woinarski $^{22}$, and Andre Zerger ${ }^{5}$

1, ${ }^{*}$ Fenner School of Environment and Society, The Australian National University, Canberra, ACT, 0200 and ARC Centre of Excellence for Environmental Decisions, The Australian National University, Canberra, ACT 0200 (Email: david.lindenmayer@anu.edu.au, Tel: 026125 0654, Fax: 026125 0757)

${ }^{2}$ The Thomas Foundation, PO Box 2048, Noosa Heads, Queensland 4567

${ }^{3}$ School of Botany, University of Melbourne, Parkville, Victoria 3010

${ }^{4}$ Institute of Wildlife Research, School of Biological Sciences, University of Sydney, NSW 2006

${ }^{5}$ CSIRO Ecosystem Sciences, GPO Box 284, Canberra, ACT 2601

${ }^{6}$ The Nature Conservancy, Suite 3-04, 60 Leicester Street, Carlton Victoria 3053, and School of Life and Environmental Sciences, Deakin University, 221 Burwood Highway, Burwood,

Victoria 3125

${ }^{7}$ Greening Australia, PO Box 74, Yarralumla, ACT 2600

${ }^{8}$ Research Institute for the Environment and Livelihoods, Charles Darwin University, Darwin, NT 0909 
${ }^{9}$ Conservation Science, The Nature Conservancy, 40 E. Main St, \#200, Bozeman, Montana 59715 USA

${ }^{10}$ School of Plant Biology, University of Western Australia, Crawley, WA 6009, and ARC Centre of Excellence for Environmental Decisions, University of Western Australia, Crawley, WA 6009

${ }^{11}$ Australian Wetlands and Rivers Centre, School of Biological, Earth and Environmental Sciences, The University of New South Wales, NSW 2052

${ }^{12}$ Department of Zoology, University of British Columbia, 6270 University Blvd., Vancouver, B.C. V6T 1Z4 Canada

${ }^{13}$ Australian Wildlife Conservancy, PO Box 8070, Subiaco East, WA 6008, and Northern Biodiversity Hub, Charles Darwin University, NT 0909

${ }^{14}$ Australian Centre for Evolutionary Biology and Biodiversity, University of Adelaide, and Science Resource Centre, Department of Environment and Natural Resources, Adelaide, SA 5005

${ }^{15}$ Conservation Science, The Nature Conservancy, 490 Westfield Road, Charlottesville, Virginia 22903 USA

${ }^{16}$ ARC Centre of Excellence for Environmental Decisions, The University of Queensland, Brisbane, Queensland 4072

${ }^{17}$ Bush Heritage Australia, Level 5, 395 Collins Street, Melbourne, Victoria 3000

${ }^{18}$ Trust for Nature, Level 5, 379 Collins Street, Melbourne, Victoria 3000

${ }^{19}$ School of Environmental Sciences, Charles Sturt University, PO Box 789, Albury, NSW 2640

${ }^{20}$ Research and Management Effectiveness Branch, Parks Victoria, Level 9, 535 Bourke Street, Melbourne, Victoria 3000 
${ }^{21}$ Centre of Environment and Energy Statistics, Australian Bureau of Statistics, ABS House, 45

Benjamin Way, Belconnen, ACT 2617

${ }^{22}$ Northern Territory Department of Natural Resources, Environment, the Arts and Sport. Current address; Charles Darwin University: PO Box 148, Christmas Island, WA 6798

Running title: Improving biodiversity monitoring 


\begin{abstract}
Effective biodiversity monitoring is critical to evaluate, learn from, and ultimately improve conservation practice. Well conceived, designed and implemented monitoring of biodiversity should: (1) deliver information on trends in key aspects of biodiversity (e.g., population changes); (2) provide early warning of problems that might otherwise be difficult or expensive to reverse; (3) generate quantifiable evidence of conservation successes (e.g., species recovery following management) and conservation failures; (4) highlight ways to make management more effective; and (5) provide information on return on conservation investment.

The importance of effective biodiversity monitoring is widely recognised (e.g., Australian Biodiversity Strategy). Yet, while everyone thinks biodiversity monitoring is a good idea, this has not translated into a culture of sound biodiversity monitoring, or widespread use of monitoring data.

We identify four barriers to more effective biodiversity monitoring in Australia. These are: (1) Many conservation programs have poorly articulated or vague objectives against which it is difficult to measure progress contributing to design and implementation problems. (2) The case for long-term and sustained biodiversity monitoring is often poorly developed and/or articulated. (3) There is often a lack of appropriate institutional support, co-ordination, and targeted funding for biodiversity monitoring. And, (4) There is often a lack of appropriate standards to guide monitoring activities and make data available from these programs. To deal with these issues, we suggest that policy makers, resource managers and scientists better and more explicitly articulate the objectives of biodiversity monitoring and better demonstrate the case for greater investments in biodiversity monitoring. There is an urgent need for improved institutional support for
\end{abstract}


biodiversity monitoring in Australia, for improved monitoring standards, and for improved archiving of, and access to, monitoring data.

We suggest that more strategic financial, institutional and intellectual investments in monitoring will lead to more efficient use of the resources available for biodiversity conservation and ultimately better conservation outcomes.

Key words: monitoring, biodiversity, National Biodiversity Strategy, management intervention, conservation effectiveness

\section{Introduction}

Biodiversity monitoring is critically important for forewarning of impending species declines and/or extinctions, creating triggers for management intervention, quantifying the effectiveness of management practices designed to conserve biodiversity, and accumulating the data to underpin metrics reflecting the status of biodiversity. These roles of biodiversity monitoring are, in turn, essential for sustaining ecosystems and ultimately underpinning the wellbeing of humanity (Daily 1997; Chivian and Bernstein 2008; Scholes et al. 2008). Despite this, biodiversity monitoring has a chequered history in environmental management and conservation practice both in Australia (e.g., ANAO 1997; 2008) and elsewhere (Kleijn and Sutherland 2003; Bernhardt et al. 2005; Kleijn et al. 2006; Muir 2010). While almost everyone thinks biodiversity monitoring is a good idea, many conservation activities are not accompanied by any biodiversity monitoring because it is overlooked in the program design and/or funds are not allocated for it to take place, or where monitoring is done, it is of poor quality and cannot inform management or 
policy. In addition, the design documents for many programs typically do not include clear, unambiguous statements of relevant, measurable and appropriately sensitive attributes that provide feedback on the program objectives. This leads to little or no sound reporting of trends in biodiversity, no clear indication of return on investment, and ultimately a limited basis for improving conservation interventions and decisions. A consequence of these deficiencies is that it has often been impossible to determine the effectiveness of many biodiversity conservation programs. Australian examples include very large investments like the Natural Heritage Trust (ANAO 1997; 2008; Hajkowicz 2009) and the Threatened Species Network Community grants, but they are paralleled by programs within many large biodiversity conservation organisations around the world (Muir 2010).

Such failures to monitor the biodiversity outcomes of what are often substantial investments is in stark contrast to investments in health and education where regular monitoring and testing have been undertaken in a co-ordinated manner for over a century with a failure to monitor seen as deficient governance.

Improved monitoring is pivotal to the success of the recently released Australian Biodiversity Strategy 2010-2030 (Natural Resource Management Ministerial Council 2010). Among other things, this strategy states:

By 2015, establish a national long-term biodiversity monitoring and reporting system. [p. $11]$ Resources available for biodiversity conservation efforts - human and financial, government and non-government-are limited. It is therefore essential that we measure, evaluate and understand the effectiveness of our biodiversity conservation efforts. This knowledge will help to ensure that our efforts are correctly prioritised and targeted, so that 
we are investing in efficient actions that will produce the greatest long-term benefits for biodiversity. [p. 40]

In order to get measurable results, we need to improve and share our knowledge of biodiversity. This involves improving the accessibility, communication and application of knowledge as well as ensuring our priorities are evidence-based. To achieve that, we need to implement robust national monitoring, reporting and evaluation measures, so that we can identify what is working - and not working — and why, and adjust our efforts accordingly. [p. 40]

While the importance of these aims is self-evident, the Australian Biodiversity Strategy 2010-2030 omits an analysis of the reasons for failure to meet similar objectives in the past and why enduring monitoring programs, and the results of long-term monitoring, remain elusive within Australia's biodiversity conservation institutions.

In this paper, we outline four broad categories of problems that need to be addressed to improve biodiversity monitoring in Australia, particularly in many government-funded programs, but which are also applicable to biodiversity monitoring by commercial enterprises (which currently goes largely unreported and/or published in the peer-reviewed ecological literature; see Buckley 1991). We discuss a range of issues nested under these broad categories of problems and outline potential solutions to them.

\section{Poorly defined objectives for biodiversity monitoring leading to poor design and implementation}

A major problem in many biodiversity monitoring programs is that objectives are vague and/or poorly specified making it difficult to develop measures to gauge performance against objectives. A key part of improved biodiversity monitoring must therefore be for policy makers 
and resource managers to articulate more explicitly their objectives and hence the key questions they need addressed (Lindenmayer and Likens 2009, Lindenmayer et al. 2011). Many other aspects of good monitoring programs, including good study design as well as what, where and how to monitor, will then follow logically from clear and unambiguous objectives and questions.

The development of appropriate objectives and associated questions of management relevance, together with the selection of appropriate entities to be measured in monitoring biodiversity programs, need to be informed by a detailed understanding of the particular population, community or ecosystem of interest. Thus, well conceived, designed and implemented monitoring programs should be characterised by both clearly articulated objectives and good questions and a conceptual model of the population, community or ecosystem being investigated (Lindenmayer and Likens 2010). Such programs should then be structured to deliver: (1) information on trends in key aspects of biodiversity (e.g., population changes); (2) appropriate early warnings of problems or threats that might otherwise be difficult, impossible and/or very expensive to reverse, including formally specified management 'triggers' or specific points where action or re-assessment is required; (3) quantifiable evidence of conservation successes (e.g., species recovery following appropriate management intervention: see Sheean $e t$ al. 2011) as well as conservation failures (e.g., Woinarski et al. 2011); (4) information on ways to make management interventions more effective; and (5) data to help guide the assessment of return on management and conservation investment. These are well known and fundamental components of successful monitoring that have been emphasised by many other workers (e.g., Nichols and Williams 2006; Gardner 2010; Magurran et al. 2010).

A significant problem in the design and implementation of monitoring programs is that a prolonged period may elapse between a given management intervention and the response of 
some elements of biodiversity, whereas most funding programs are only short-term. A number of strategies can help deal with this "slow feedback" loop including using cross-sectional approaches in monitoring design to generate rapid initial insights (Lindenmayer and Likens 2010), identifying indicators that respond rapidly to management (Gardner 2010), and employing predictive modelling to provide an early indication of likely outcomes and formulate additional hypotheses for testing (Jones et al. 2011).

Although there are many problems associated with the design of biodiversity monitoring programs, there are nevertheless examples of good programs (e.g., Black and Groombridge 2010) and it is critical to use them as exemplars to improve other existing and new programs. For example, arguably one of the best examples of long-term biodiversity monitoring in Australia is on populations of large macropods. That work underpins the kangaroo harvesting industry and setting ecologically sustainable annual quotas. Population data are gathered regularly, both through aerial survey and harvest returns. These data are critical because populations of kangaroos fluctuate markedly in response to droughts and wet years. Setting harvest quotas typically involves integrating at least six types of monitoring data: (1) current population trends, (2) previous harvest levels, (3) current and past climatic conditions, (4) the level of noncommercial harvest, (5) the size of the population exempt from harvesting, and (6) other forms of mortality (apart from harvesting).

In addition to the role of exemplar projects to guide improved biodiversity monitoring, there may be value in completing meta-analyses and systematic reviews to determine what needs to be monitored and what conclusions can be safely drawn without further monitoring. There also may be value in establishing pilot programs to determine the most appropriate designs and likely effectiveness of new monitoring programs. Similarly, the design of monitoring programs 
might be improved if they embrace some business approaches (Black and Groombridge 2010) like auditing expenditure and developing metrics that highlight return on investment (including determining when monitoring programs cease to be effective).

It is not possible to monitor all things, everywhere. Well informed decisions need to be made about when monitoring is appropriate and when there is no strong ecological, environmental or economic case to instigate (or maintain pre-existing) monitoring programs. Decision theory underpinned by good ecological information can assist in making appropriate decisions about when monitoring programs are and are not appropriate, and why (McDonaldMadden et al. 2010).

While well articulated objectives and questions often underpin effective biodiversity monitoring programs, mandated, surveillance monitoring in which there are no a priori questions (see Lindenmayer and Likens 2010) can sometimes be useful in tackling environmental problems that were unforeseen at the commencement of a project (Wintle et al. 2010). The chance discovery of the impacts of pesticides on eggshell thinning in birds in North America is a classic example of a serendipitous finding from surveillance monitoring (Grier 1982). This highlights the challenge of finding new and better ways to link data and insights from mandated surveillance monitoring programs and question-driven monitoring programs.

\section{Resolving arguments about what to monitor}

A longstanding problem with the design and implementation of biodiversity monitoring programs has been the protracted debates about what to monitor (Gardner 2010; Lindenmayer and Likens 2011). "Solutions to this problem are: (1) to ensure that the entities targeted for monitoring are those which can address the objectives and questions articulated at the outset, and, (2) to prioritise the entities targeted for monitoring. In many cases, these entities will be 
those which provide key information about the condition, function and integrity of a given system and which help answer key questions of management relevance including the effectiveness (and cost-effectiveness) of management.

In many biodiversity monitoring programs it will be essential to quantify both biodiversity responses and key attributes of management interventions (e.g., grazing regime, burning regime, pest control) as well as how much financial investment has occurred at monitoring sites. Both kinds of data are critical for linking the response of biodiversity to management practices and determining the cost-effectiveness of management interventions. This is in contrast to some large-scale environmental programs in Australia like the Natural Heritage Trust where crude estimates of management inputs (e.g., km of fencing) were gathered but little or no information on the actual change in management interventions, nor the response of biodiversity to management interventions, was collected (ANAO 1997; 2008: see also Robins and Kanowski 2011).

Improving monitoring through reviews and embracing Adaptive Monitoring

Even when robust monitoring programs are based on good questions of management relevance and target an appropriate subset of entities for measurement, there is still a need to review them regularly. This is to ensure they can be improved, for example, by adding new entities to be measured as a result of new insights that have been gained or when new questions of management relevance become important. Such a cycle of continuous improvement in monitoring programs has been termed “Adaptive Monitoring” (Lindenmayer and Likens 2009, 2011) in which a monitoring program can evolve and develop in response to new information, new questions, or to improve obsolete approaches and monitoring protocols. A critical aspect of Adaptive Monitoring is the need to ensure that a change of biodiversity monitoring protocols 
does not breach the integrity of the long-term nature of the data record. Calibration of different field methods can help solve this potential problem (Buso et al. 2000).

\section{A poorly developed and articulated case for biodiversity monitoring}

It is possible that one of the key factors contributing to the poor record on biodiversity monitoring in Australia (and indeed elsewhere around the world) is that governments see no social or economic imperative to support it. Important exceptions for which governments accept the need to monitor include harvested fish populations, and populations of other species subject to sustainable use (e.g., large macropods). A critical task then is to persuade governments that there is socio-economic benefit and moral and/or legal responsibility (e.g., under State, national or international legislation and agreements) to monitor other components of biodiversity and ecosystems. Hence, scientists and others need to more strongly advocate and demonstrate the importance of biodiversity monitoring. It also will be important to communicate the risks of not conducting biodiversity monitoring programs such as failing to detect ecological surprises that are difficult and/or costly to reverse. Invasive species impacts are a particularly good example because biodiversity monitoring for early detection and subsequent control can obviate often expensive and ineffective control attempts after establishment (McNeely et al. 2003). For

example, biodiversity monitoring in Darwin Harbour led to the early detection of an invasion by black-striped mussel (Mytilopsis sallei) - a potentially economically-devastating exotic species. Thus, mussel infestation was discovered when populations were small enough to be eradicated (Bax et al. 2002) thereby saving millions of dollars had the mussel spread further.

Lessons learned from human population health (Chivian and Bernstein 2008) are relevant in the context of advocacy biodiversity monitoring. In an editorial in Science on science-based health care, Zhu (2010) states, "a traditional misconception is that spending on health is a social 
burden, instead of being a strategic investment essential for each nation's socioeconomic development". This argument is equally valid for the conservation and the protection of biodiversity. Indeed, recent work by the United Nations (e.g., European Communities 2008; United Nations Environment Program 2010) shows the economic and employment benefits of appropriate environmental investment are substantial while the costs of inaction are significant.

The social and economic benefits of biodiversity monitoring must be communicated in a range of forms and for a range of audiences. Some forms of communication, like scientific articles, are rarely read by important partners in monitoring programs such as resource managers and policy makers (Gibbons et al. 2008). Therefore, scientists and other groups need to be solidly engaged in communication efforts arising from monitoring programs. Increasingly this must include social media as a means of reaching a wider audience - $\mathrm{a}$ form of communication with which few scientists are currently comfortable or accomplished. There may be a role for 'science translators' that work across the science-policy divide to help policy makers and resource managers interpret key findings, make monitoring data more useful and better integrate scientific evidence into policy. Organisations like the Canadian Forest Service have had a long history of this kind of professional science communicator. Notably, in the USA, the philanthropic community has an increasing responsibility for communicating the importance of monitoring (e.g., see www.charitynavigator.org). There is a need to be aware that the results of monitoring programs can sometimes be misused and misquoted to support particular political and other agendas (Fitzsimons 2011).

There is an important role for non-government organisations (NGOs) in advocacy for more and better biodiversity monitoring. While, in Australia, most monitoring is undertaken by governments or through collaboration with governments, NGOs may be best placed to monitor 
the performance of government with respect to the success of management interventions and biodiversity responses. Indeed, regular reporting of government biodiversity monitoring performance may be a powerful incentive for action.

\section{Lack of appropriate institutional support, co-ordination, and targeted funding for biodiversity monitoring.}

Improving institutional support for biodiversity monitoring

Many biodiversity monitoring programs owe their success to the enthusiasm of an individual project "champion" (Lindenmayer and Likens 2010). However, the fact that the success of many monitoring programs relies upon a few individuals often underscores a paucity of institutional support, a lack of long-term funding, and a paucity of appropriate collaborative partnerships. Part of the solution to this set of problems might be to considerably strengthen institutional support and better deliver on key roles such as:

1. Co-ordinating activities among different biodiversity monitoring programs, including mapping what monitoring is being done where and identifying efficiencies and synergies among programs.

2. Improving objective setting, experimental and statistical design, and statistical analyses of monitoring datasets (including the use of recent innovations like occupancy, presence and detection modelling).

3. Developing, implementing and maintaining data collection protocols and data standards, including improving data storage, data accessibility and registers of datasets.

4. Improving reporting of data and results from monitoring programs, particularly in a form that is useful for management. 
5. Brokering partnerships which are fundamental to the success of monitoring programs.

6. Fostering appropriate institutional and scientific cultures to ensure that monitoring programs are maintained in the long-term, including assisting with succession planning as the project champions retire, and new project leaders are sought.

7. Assessing the cost-effectiveness of expenditure on biodiversity conservation.

8. Advocating for increased levels of targeted funding for biodiversity monitoring.

An increased focus on training within strengthened institutions is urgently needed to improve skill sets essential for good monitoring but which are currently in decline like natural history and taxonomy (see Noss 1996) Training also needs to improve other areas of expertise needed for biodiversity monitoring such as experimental design, statistical analysis and database management.

There are some useful examples of potential institutional models. For instance, the Australian Bureau of Meteorology has many of the characteristics of an appropriate institution: it is a statutory body, has a legislative mandate, and uses cutting edge science and modelling systems as key parts of its work. Another example is the Australian Bureau of Statistics which has statutory independence from policy bodies and is mandated to report on an array of measures including many associated with the Australian environment. Finally, in an ecotoxicology context, many nations have a dedicated Environmental Protection Agency (or equivalent) that have a well established track record of long-term data collection (under appropriate data standards) followed by rigorous analysis and reporting of those data.

\section{Tackling problems with funding}


A lack of funding is a common reason why many monitoring programs fail. Moreover, there is typically a mismatch between the long time-frames needed for biodiversity monitoring and the short time-frames of funding and political cycles. New kinds of funding models are needed to overcome this hurdle such as long-term trusts (e.g., Barnes et al. 2008) and/or foundation-style support. Some innovative funding models employed elsewhere may be worth investigating and adapting for widespread use in Australia (Lindenmayer 2007). For example, proceeds from lotteries to fund environmental programs are common elsewhere; they are used in New Zealand, South Africa, Ontario and Alberta in Canada, and Colorado in the USA. Some US states have other approaches to funding environmental projects. Florida has a tax on real estate transactions and Missouri a sales tax on some non-essential items. The Bahamas has a hotel tax that partially funds their national parks system (including biodiversity monitoring). Quito in Ecuador has a water utility tax that funds conservation in the headwaters. Costa Rica and Micronesia have instituted "trust funds" to bridge the gap in funding for protected area systems.

Part of the problem of ongoing funding for biodiversity monitoring might be resolved if monitoring had greater political support and became a mainstream concern and not a peripheral issue as it is currently. Greater political support for sustained and consistent biodiversity monitoring will eventuate if: (1) the economic, social and environmental case can be better developed and advocated, (2) as outlined above, monitoring can demonstrate return on conservation investment and, conversely, the costs of not doing monitoring, and, (3) there is a broad constituency advocating for it.

Many strategies are needed to generate greater support for biodiversity monitoring. The creation of a set of national environmental accounts (sensu Wentworth Group of Concerned Scientists 2008) would rapidly elevate the importance of biodiversity monitoring and hence 
support for such activities, although such accounts will only be as good (or bad) as data that underpin them. Large-scale economic changes like those associated with the emerging initiatives like the "green economy" (United Nations Environment Program 2010) also may provide important catalysts to generate greater political support for biodiversity monitoring.

The longevity and success of monitoring programs might be increased if it is a formal, or mandated, requirement under international conventions, legislation, or development consent (Lindenmayer and Gibbons 2004). Indeed, there is already considerable money and effort expended by some private companies as part of their environmental obligations, either before development, or as mandatory monitoring after development (Buckley 1991). However, the quality of much of this work remains largely unassessed, and the results are rarely reported in any accessible way (Buckley 1991) (Lindenmayer and Gibbons 2004). We suggest that part of the obligation of undertaking this work must be for it to be peer-reviewed and published so that it can be included in a broader assessment of the status of biodiversity in Australia.

An important aspect of funding is that the level of financial investment in biodiversity monitoring needs to be scaled according to the size of a given conservation initiative (Franklin et al. 1999; Lindenmayer and Likens 2010). In addition, the level of investment in monitoring needs to be matched to the level of inference needed as well as to factors such as risk, uncertainty, and whether a project is being treated as a pilot or proof of demonstration project. Some organisations like the Australian Wildlife Conservancy invest $\sim 20 \%$ of their annual operating budget on monitoring biodiversity response to management interventions. However, in many cases $\sim 5-10 \%$ of biodiversity conservation program funding might be appropriate to dedicate to monitoring.

Partnerships as a critical part of monitoring programs 
Biodiversity monitoring programs require the integration of both good science and good management practice (Russell-Smith et al. 2003). Unfortunately, academic scientists often do not engage in biodiversity monitoring programs. However, they can assist in many key areas including experimental design, database design, data analysis, data interpretation, and reporting. It may be particularly important for academic scientists to engage with biodiversity monitoring undertaken as part of resource development projects by private industry, in part to ensure the scientific quality of such work, but also to promote its publication in the peer-reviewed literature.

Academic scientists also can provide guidance for citizen scientists and community groups to ensure that data they gather are of high quality and are useful. There are good reasons for the lack of scientific engagement in monitoring. As noted by Nisbet (2007, p. 790): “Monitoring does not win glittering prizes. Publication is difficult, infrequent and unread'. It is clear then that changes in the rewards systems for academic scientists are needed to catalyse their involvement in biodiversity monitoring programs undertaken not only by government agencies (Gibbons et al. 2008) but also by commercial companies.

Successful biodiversity monitoring programs will be those connecting individuals from two or more of the following: government agencies, non-government conservation organisations, universities, and community groups. This is to ensure that monitoring programs pass the "test of management relevance" (sensu Russell-Smith et al. 2003; McDonald-Madden et al. 2010) and are therefore more likely to be sustained in the long term. Thus, monitoring needs to address questions that managers not only want answers to but are willing to act on when they have those answers. The bird monitoring work supported through Birdlife Australia is an example of a successful cross-institutional partnership (e.g., Barrett et al. 2003).

\section{Improved data standards}


There are many kinds of biodiversity monitoring programs around Australia and they are characterised by marked differences in experimental or survey design, field protocols, entities targeted for measurement, and the spatial and temporal scales of implementation. Such differences have led to a paucity of national datasets to quantify national trends, although the Atlas of Australian Birds (Barrett et al. 2003) and the national count of large macropods are two of a handful of notable exceptions. Similarly, the Australian Ecological Knowledge and Observation System (AEKOS) through the ecoinformatics data portal for the Terrestrial Ecosystem Research Network is collating datasets for national integration, access and reuse (see http://www.tern.org.au/). Nevertheless, the current paucity of national biodiversity datasets in Australia is in stark contrast with other types of monitoring data such as those on economic indicators and human populations for which there have been decades of consistent time series information.

Given the disparity in biodiversity monitoring approaches, some workers have called for national (and even international) standards to be developed for biodiversity monitoring programs and data gathering. For example, the Conservation Measures Partnership (www.conservationmeasures.org) is seeking to get global standards for adaptive management including data standards for monitoring. Similarly, the System of Environmental Economic Accounting (SEEA 2003) is a formal approach to setting international environmental standards. There are also some useful guides for biodiversity monitoring data standards that can be drawn from other areas of environmental monitoring such as the water standard that has been developed by the Bureau of Meteorology (http://www.bom.gov.au/water/standards/aboutWASB.shtml). Notably, any standards that are developed would not remain static but evolve over time. 
While data standards are undoubtedly important, we suggest it would be inappropriate to demand that precisely the same full suite of entities should be gathered in all biodiversity monitoring programs across Australia. There are many obvious reasons for this. The principal one is that entities (such as particular groups of biota) that are sensible for measurement in, for example, the wet forests of south-western Tasmania, will be markedly different from those entities appropriate in the tropical savannas of northern Australia. Different problems, different questions of management relevance, and different biota in different ecosystems mean that a diversity of monitoring programs will be needed to match monitoring design with monitoring objectives. We therefore suggest that a common set of standards should generally focus on higher-order issues such as objective setting, statistical design, metadata and data access as exemplified by the guidelines provided by the Australian National Data Service (http://www.ands.org.au), rather than finer levels of detail (e.g., particular entities to be measured).

Biodiversity monitoring data are often used in ways that are different to those initially anticipated. Hence, there is considerable value in gathering monitoring information in electronic ways that facilitate later use by others (Pullin and Salafsky 2010). For example, the methods used in field data collection in the long-term biodiversity monitoring study in the Yukon by (Krebs et al. 2001) have been documented and published so that others can repeat data collection protocols at a later date if needed. This is particularly important for large monitoring datasets that have been gathered over a prolonged period and where the champion for that program aims to retire but has a desire for the program to continue and/or wants information to be used by others in the future. As an example, the techniques for monitoring rufous scrub-bird (Atricornis rufescens) were described in such detail by Ferrier (1984) that an independent group was able to 
reproduce the survey almost exactly in 2010 . So good were the instructions that they found many scrub-birds calling from exactly the same sites a quarter of a century later and that scrub-bird density has not changed at all in that time (Newman 2010). This example also highlights the potential value of improved co-ordination and succession planning roles for institutions charged with improving biodiversity monitoring in Australia.

\section{The importance of new technology}

The development of new technologies will promote the rapid collection of large amounts of field data from biodiversity monitoring programs. Some of these new technologies will facilitate connections between on-ground monitoring methods and data collection with other large-scaled approaches like remote sensing (e.g., Youngentob et al. 2011). In addition, genomic analysis of floral, faunal and environmental samples (soils and water) are also rapidly developing and have the capacity to use surrogate species to rapidly monitor ecosystem health (e.g., Pointing et al. 2009). However, it is crucial to link these approaches through well articulated objectives and to pose good scientific questions, otherwise there is a risk of being overwhelmed in a "sea of data" and failing to make critical discoveries. Shanklin (2010) provides an example of this problem from studies of the ozone layer.

Improving the availability of monitoring data

Some workers have made calls to make all biodiversity monitoring data publicly available and a condition of receiving public funding and of publishing scientific articles (Pullin and Salafsky 2010). Indeed, this is an aim of the Terrestrial Ecosystem Research Network initiative of the Australian Government (see http://www.tern.org.au/) and the Atlas of Living Australia (http://www.ala.org.au/). There is also a need to ensure that the datasets from biodiversity monitoring programs undertaken by private companies are made publicly available - possibly as 
a mandated requirement of resource use and related kinds of projects. However, an important issue is the maintenance of intellectual property and the development of new ways to allow scientists and others who have gathered data to be able to publish it in a timely way before it is made available publicly. Resolution of intellectual property and data licensing issues should help reduce instances of misuse of data. There also may be value in examining new kinds of reward systems for workers in academic institutions that acknowledge the contributions of scientists and others who have collected datasets that are used by others. An example would be new kinds of metrics which reflect the amount of use of a given dataset by others and which underpin rewards for levels of data usage. However, high quality archiving of data and database management will need to be a key part of biodiversity monitoring programs to ensure that this can occur (Whitlock 2010). Similarly, we suggest there is a need for the editors of journals to demand that the authors of articles acknowledge the sources of data, perhaps through an explicit statement of origin of datasets using approaches akin to ethics approval statements that are now common in many publications.

\section{General recommendations and concluding comments}

It is clear that we need more biodiversity monitoring for more effective biodiversity conservation in Australia. For additional monitoring to be far better than it generally has been to date, we need better training of those involved in monitoring programs and considerably strengthened institutions to better co-ordinate, implement and maintain monitoring programs. This must include co-ordination with private companies which often undertaken biodiversity monitoring programs but the results of which are rarely subject to rigorous external assessment and the outcomes only infrequently reported in the scientific literature. Without better training of those involved in monitoring programs and considerably strengthened institutions, statements 
made about national biodiversity reporting systems and frameworks in the Australian Biodiversity Strategy 2010-2030 (Natural Resource Management Ministerial Council 2010) will amount to little more than vacuous platitudes. On this basis, we make four broad recommendations for improving biodiversity monitoring in Australia and, in turn, helping the Australian Biodiversity Strategy 2010-2030 to achieve its stated goals.

1. The effectiveness of biodiversity conservation must be measured by rigorous monitoring and reporting on trends in species populations, ecosystems and threats. Thus, in much the same way as business conducts sound financial practice through monitoring and the System of National Accounts is used to hold the Australian Government accountable for the management of the economy, there needs to be assessments of management effectiveness and environmental return on investment (Black and Groombridge 2010).

2. We need to identify new ways to better communicate the importance of biodiversity conservation to politicians and society in general and, in turn, to garner the political and community support needed for biodiversity monitoring programs.

3. Biodiversity monitoring is chronically under-funded and this needs to be urgently rectified. Increased funding for biodiversity monitoring programs could, for example, be derived from monies quarantined from development projects, or as part of biodiversity offsets now implemented in most Australian states and proposed nationally (Commonwealth of Australia 2009). There is also a need for dedicated research explicitly aimed at identifying other ways to sustain long-term funding for biodiversity monitoring programs that are best suited to the Australian political and financial context. 
4. There is a critical need to significantly improve institutions so they can far better support biodiversity monitoring in Australia.

a. First, there is an urgent need for institutions to: invest in and maintain longterm biodiversity monitoring programs, better curate long-term datasets, develop national standards for monitoring, identify and develop standards for best practice monitoring, broker partnerships between individuals and organisations, and foster succession planning in existing long-term programs.

b. Second, institutions need to improve training for new generations of ecologists with skills essential to establish and maintain long-term biodiversity monitoring programs, to communicate the need and value of biodiversity monitoring programs, and to foster innovation in continuously improving monitoring programs.

Our hope is that solutions to the problems we have identified in this paper might be adopted by policy makers, resource managers and scientists and that better biodiversity monitoring and enhanced reporting and acting on monitoring outcomes take place - ultimately leading to better outcomes for biodiversity conservation in this country.

\section{Acknowledgments}

This paper arose from a national meeting on biodiversity monitoring in Australia held in February 2011 and sponsored by The Thomas Foundation. Claire Shepherd assisted in many aspects of the preparation of this paper.

\section{References}

ANAO. (1997) Commonwealth Natural Resource Management and Environment Programs: Audit Report No. 36 1996-97. Australian National Audit Office, Canberra. 
ANAO. (2008) Regional Delivery Model for the Natural Heritage Trust and the National Action Plan for Salinity and Water Quality: Audit Report No. 21 2007-08. Australian National Audit Office, Canberra.

Barnes P., Costanza R., Hawken P., Orr D., Ostrom E., Umana A. \& Young O. (2008) Creating an Earth Atmopsheric Trust. Science 319, 724.

Barrett G. W., Silcocks A., Barry S., Cunningham R. \& Poulter R. (2003) The New Atlas of Australian Birds. Birds Australia, Melbourne.

Bax N., Hayes K., Marshall A., Parry D. \& Thresher R. (2002) Man-made marinas as sheltered islands for alien marine organisms: establishment and eradication of an alien marine species. In: Turning the tide: the eradication of invasive species (eds C. R. Veitch and M. N. Clout) pp. 2639. IUCN SSC Invasive Species Specialist Group, Gland, Switzerland.

Bernhardt E. S., Palmer M. A. \& Allan J. D. (2005) Synthesizing US river restoration projects. Science 308, 636-7.

Black S. \& Groombridge J. (2010) Use of a business excellence model to improve conservation programs. Conserv. Biol. 6, 1448-58.

Buckley, R. (1991). Auditing the precision and accuracy of environmental impact predictions in Australia. Environmental Monitoring and Assessment 18, 1-24.

Buso D. C., Likens G. E. \& Eaton J. S. (2000) Chemistry of precipitation, stream water and lake water from the Hubbard Brook Ecosystem Study: A record of sampling protocols and analytical procedures. In: General Tech. Report NE-275 pp. 1-52. USDA Forest Service, Northeastern Research Station, Newtown Square, Pennslyvania.

Chivian E. \& Bernstein A. (2008) Sustaining life. How human health depends on biodiversity. Oxford University Press, Oxford, England. 
Commonwealth of Australia. (2009) The Australian Environment Act - An Independent Review of the Environment Protection and Biodiversity Conservation Act 1999. Australian Government Department of the Environment, Water, Heritage and the Arts, Canberra.

Daily G. C. (1997) Nature's Services: Societal Dependence on Natural Ecosystems. Island Press, Washington, D.C.

European Communities. (2008) The economics of ecosystems and biodiversity. European Communities, Wesseling, Germany.

Ferrier S. (1984) The status of the Rufous Scrub-bird Atrichornis rufescens: habitat, geographical variation and abundance. University of New England, Armidale.

Fitzsimons J. (2011 in press) Cows, cockies and atlases: use and abuse of biodiversity monitoring in environmental decision making. In: Improving Biodiversity Monitoring in Australia (eds D. B. Lindenmayer and P. Gibbons). CSIRO Publishing, Melbourne.

Franklin J. F., Harmon M. E. \& Swanson F. J. (1999) Complementary roles of research and monitoring: lessons from the U.S. LTER Program and Tierra del Fuego. Symposium Paper. In: Toward a Unified Framework for Inventorying and Monitoring Forest Ecosystem Resources, Guadalajara, Mexico, November 1998.

Gardner T. (2010) Monitoring forest biodiversity. Improving conservation through ecologically responsible management. Earthscan, London.

Gibbons P., Zammit C., Youngentob K., Possingham H. P., Lindenmayer D. B., Bekessy S., Burgman M., Colyvan M., Considine M., Felton A., Hobbs R., Hurley C., McAlpine C., McCarthy M. A., Moore J., Robinson D., Salt D. \& Wintle B. (2008) Some practical suggestions for improving engagement between researchers and policy-makers in natural resource management. Ecol. Manage. Restor. 9, 182-6. 
Grier J. W. (1982) Ban of DDT and subsequent recovery of reproduction in bald eagles. Science 218, $1232-4$.

Hajkowicz S. (2009) The evolution of Australia's natural resource management programs: Towards improved targeting and evaluation of investments. Land Use Policy 26, 471-8. Jones J. P. G., Collen B., Atkinson G., Baxter P. W. J., Bubb P., Illian J. B., Katzner T. E., Keane A., Loh J., McDonald-Madden E., Nicholson E., Pereira H. M., Possingham H. P., Pullin A. S., Rodrigues A. S. L., Ruiz-Gutierrez V., Sommerville M. \& Milner-Gulland E. J. (2011) The why, what, and how of global biodiversity indicators beyond the 2010 target. Conserv. Biol. 25, 4507.

Kleijn D., Baquero R. A., Clough Y., Diaz M., De Estaban J., Fernandez F., Gabriel D., Herzog F., Holzchuh A., Johl R., Knop E., Kruess A., marshall E. J., Steffan-Dewenter I., Tscharntke T., Verhulst J., West T. M. \& Yela J. L. (2006) Mixed biodiversity benefits of agri-environment schemes in five European countries. Ecol. Lett. 9, 243-54.

Kleijn D. \& Sutherland W. J. (2003) How effective are European agri-environment schemes in conserving and promoting biodiversity? J. Appl. Ecol. 40, 947-69.

Krebs C. J., Boutin S. \& Boonstra R. (2001) Ecosystem Dynamics of the Boreal Forest: The Kluane Project. Oxford University Press, New York.

Lindenmayer D. B. (2007) On Borrowed Time: Australia's Environmental Crisis and What We Must Do About It. CSIRO Publishing and Penguin Publishing, Melbourne. Lindenmayer D. B. \& Gibbons P. (2004) On charcoal, the increased intensity of logging and a flawed Environmental Assessment process. In: Conservation of Australia's Forest Fauna (ed D. Lunney) pp. 56-62. Royal Zoological Society of New South Wales, Sydney. 
Lindenmayer D. B. \& Likens G. E. (2009) Adaptive monitoring: a new paradigm for long-term research and monitoring. Trends Ecol. Evol. 24, 482-6.

Lindenmayer D. B. \& Likens G. E. (2010) Effective Ecological Monitoring. CSIRO Publishing and Earthscan, Melbourne and London.

Lindenmayer D. B. \& Likens G. E. (2011) Direct measurement versus surrogate indicator species for evaluating environmental change and biodiversity loss. Ecosystems 14, 47-59.

Lindenmayer D. B., Likens G. E., Meizis, L. \& Haywood, A. (2011). Adaptive monitoring in the real world: Proof of concept. Trends Ecol. Evol. (in press).

Magurran A. E., Baillie S. R., Buckland S. T., Dick J. M., Elston D. A., Scott E. M., Smith R. I., Somerfield P. J. \& Watt A. D. (2010) Long-term datasets in biodiversity research and monitoring: assessing change in ecological communities through time. Trends Ecol.Evol. 25, $574-82$.

McDonald-Madden E., Baxter P. W. J., Fuller R. A., Martin T. G., Game E. T., Montambault J. \& Possingham H. P. (2010) Monitoring does not always count. Trends Ecol. Evol. 25, 547-50. McNeely J. A., Neville L. E. \& Rejmanek M. (2003) When is eradication a sound investment? Conservation in Practice 4, 30-41.

Muir M. J. (2010) Are we measuring conservation effectiveness? Report to Conservation Measures Partnership, www.conservationmeasures.org.

Natural Resource Management Ministerial Council. (2010) Australia's Biodiversity Conservation Strategy 2010-2030. Australian Government Department of Sustainability, Environment, Water, Population and Communities, Canberra.

Newman N. (2010) Rufous Scrub-bird Surveys - Barrington/Gloucester Tops IBA - 15 to 17 September 2010. Report to Hunter River Bird Observers' Club. In: 
http://www.hboc.org.au/resources/documents/RSB\%20Sep\%202010\%20interim\%2520report.pd. Hunter River Bird Observers' Club.

Nichols J. D. \& Williams B. K. (2006) Monitoring for conservation. Trends Ecol. Evol. 21, 66873.

Nisbet E. (2007) Cinderella science. Nature 450, 789-90.

Noss R. (1996) The naturalists are dying off. Conserv. Biol. 10, 1-3.

Pointing S. B., Chan Y., Lacap D. C., Lau M. C. Y., Jurgens J. A. \& Farrell R. L. (2009) Highly specialized microbial diversity in hyper-arid polar desert. Proc. Natl. Acad. Sci. USA 106, 19964-9.

Pullin A. S. \& Salafsky N. (2010) Save the whales? Save the rainforest? Save the data! Conserv. Biol. 24, 915-7.

Robins L. \& Kanowski P. (2011) Crying for our Country: eight ways in which "Caring for our Country" has undermined Australia's regional model for natural resource management. Aust. $J$. Environ. Manage. in press.

Russell-Smith J., Whitehead P. J., Cook G. D. \& Hoare J. L. (2003) Response of Eucalyptusdominated savanna to frequent fires: lessons from Munmarlary 1973-1996. Ecol. Monogr. 73, $349-75$.

Scholes R. J., Mace G. M., Turner W., Geller G. N., Jurgens J., Larigauderie A., Muchoney D., Walther B. A. \& Mooney H. A. (2008) Toward a global biodiversity observing system. Science 321, 1044-5.

SEEA. (2003) Handbook of National Accounting: Integrated Environmental and Economic Accounting 2003. United Nations Statistics Division, New York Shanklin J. (2010) Reflections on the ozone hole. Nature 465, 34-5. 
Sheean V. A., Manning A. D. \& Lindenmayer D. B. (2011) An assessment of scientific approaches towards species relocations in Australia. Austral Ecol., doi 10.1111/j.4429993.2011.02264.x.

United Nations Environment Program. (2010) Green Economy Report: A Preview. United Nations Environment Program, Châtelaine-Switzerland.

Wentworth Group of Concerned Scientists. (2008) Accounting for Nature. A Model for Building the National Environmental Accounts of Australia. Wentworth Group of Concerned Scientists, Sydney.

Whitlock M. C. (2010) Data archiving in ecology and evolution: best practices. Trends Ecol. Evol. 26, 61-5.

Wintle B. A., Runge M. C. \& Bekessy S. A. (2010) Allocating monitoring effort in the face of unknown unknowns. Ecol. Lett. 13, 1325-37.

Woinarski J. C. Z., Legge S., Fitzsimons J. A., Traill B. J., Burbidge A. A., Fisher A., Firth R. S. C., Gordon I. J., Griffiths A. D., Johnson C. D., McKenzie N. L., Palmer C., Radford I., Rankmore B., Ritchie E. G., Ward S. \& Ziembicki M. (2011) The disappearing mammal fauna of northern Australia: context, cause, and response. Conserv. Lett. 4, 192-201. Youngentob K. N., Wallis I. R., Lindenmayer D. B., Wood J. T., Pope M. L. \& Foley W. J. (2011) Foliage chemistry influences tree choice and landscape use of a gliding marsupial folivore. J. Chem. Ecol. 37, 71-84.

Zhu C. (2010) Science-based health care. Science 327, 1429. 